\title{
Asthma at the interface: bridging the gap between general practice and a district general hospital
}

Ian Charlton, Antonios G Antoniou, Jean Atkinson, M J Campbell, Ellen Chapman, Terry Mackintosh, David Schapira

\begin{abstract}
A clinic supervised by a nurse, using principles originally developed in general practice, was established in the paediatric department of a district general hospital. A randomised controlled study was conducted comparing children admitted with asthma or attending outpatients who were given a patient education programme and self management plan (intervention group) with a control group. The study comprised 91 patients aged 3-14 years admitted for asthma or attending a hospital outpatient department from November 1989 to November 1990. Seventy seven patients completed the study and kept diaries for a median of 283 days. Patients in the intervention group had significantly less restriction of activity $(95 \%$ confidence interval (CI) -0.27 to -0.01 ) and fewer episodes of peak flow below $30 \%$ of best $(95 \%$ CI 0.03 to $1 \cdot 17)$. Patients in the intervention group were more likely to make the correct response to an acute exacerbation of their asthma than the control group ( $71 \%$ v 47\%, 95\% CI 9.51 to 39.1). The intervention group had fewer school absences and fewer home visits by a general practitioner. There was an increase in the readmission rate for the intervention group. A subgroup of patients who self managed by doubling their use of inhaled steroids during an exacerbation performed better than those patients who only increased their bronchodilator or were managed on salbutamol or sodium cromoglycate alone.

Improvements in patient follow up and the structure of the self management plans used, particularly changing the peak flow level at which inhaled steroids are doubled, may further improve the outcome of patients attending the asthma clinic. (Arch Dis Child 1994; 70: 313-318)
\end{abstract}

Asthma causes considerable morbidity despite the widespread use of bronchodilators and prophylactic treatment. ${ }^{1-4}$ Most noticeable in recent years has been the $167 \%$ increase in paediatric asthma admissions ${ }^{5}$ without any alteration in patient morbidity. Many of these patients bypass their general practitioner. ${ }^{6}$

Despite an abundance of educational material patients remain confused about the management of their asthma. ${ }^{7}$ In part this may be due to the variation in care provided by general practitioners ${ }^{8}$ and hospital clinicians. ${ }^{9} 10$ After reviewing the prevalence and severity of asthma, Anderson et al concluded that the biggest impact on the management of asthma would come from a coordinated approach by all members of a district health care system. ${ }^{11}$

A number of American studies have demonstrated improvements in asthma care in paediatric departments when self management programmes have been implemented. ${ }^{12-14}$ In Britain and New Zealand there has been mixed success using educational programmes administered by specially trained staff. ${ }^{15-17}$

In a study of patient attitudes Sibbald concluded that their was no single factor responsible for patient morbidity and that patients required 'simple pragmatic advice'.7 Interestingly the two studies that report the greatest success have used patient self management plans based on peak flow recordings as a way of addressing this issue. ${ }^{18} 19$ Both these studies were, however, uncontrolled.

It would appear that if we are to influence the morbidity associated with asthma, then an organised approach to the management of this condition is required. This organisation needs to be at patient, general practitioner, and at a hospital level.

This study aimed to assess a nurse run asthma clinic in the department of paediatrics at the Royal Hampshire County Hospital, Winchester, using principles originally developed in general practice. ${ }^{2021}$ The effectiveness of the clinic was assessed by examining changes in patient morbidity as measured by symptom and peak flow diary cards and a morbidity questionnaire. ${ }^{22}$

\section{Patients and methods}

Children aged between 3 and 16 years, who required admission for their asthma or attended the paediatric outpatients department were eligible for the study. The children were randomised on the basis of age, sex, and whether they used asthma prophylaxis before entering the study.

Children and the accompanying parent were seen on the ward or in outpatient sessions, during office hours, by the asthma nurse. The nurse had attended a three day course at an asthma training centre in Southampton.

\section{ASTHMA NURSE INTERVENTION}

Those patients randomised to the asthma nurse received a standardised interview and assessment that involved completing a questionnaire $^{22}$ and history of the child's asthma, allergy status, provoking factors, regular medications, and current symptoms. 

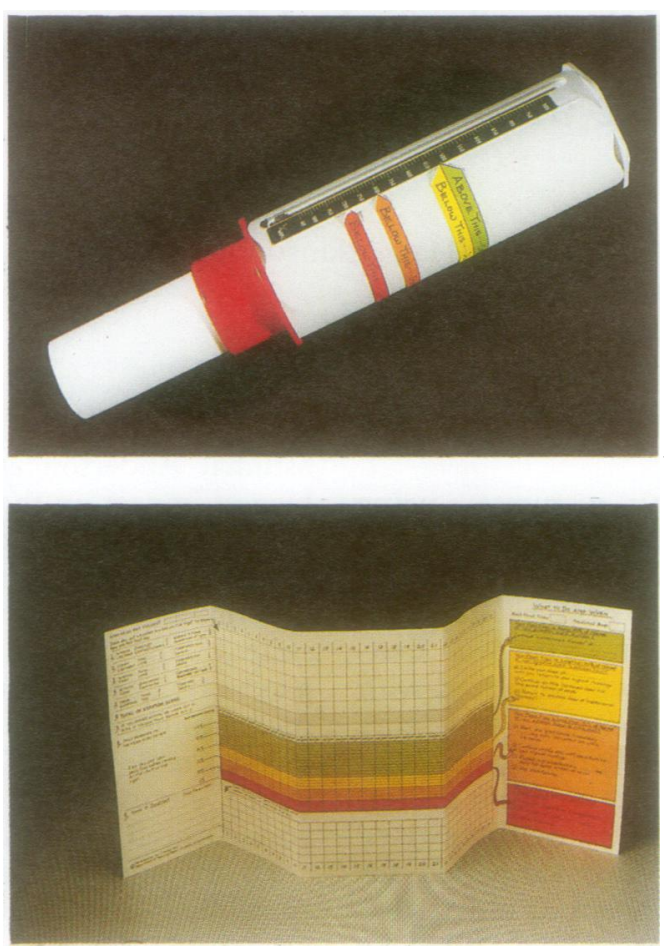

Upper: peak flow meter. Lower: asthma self management plan.

- Green zone: Your peak flow is above $70 \%$ of normal or your symptom score is under 6 ... continue 'maintenance therapy' of ....

- Yellow zone: Your peak flow is less than $70 \%$ of normal or your symptom score is between 6 and $9 \ldots$.

(a) Double your dose of ... until you return to your highest reading.

(b) Continue on this dose for the same number of days.

(c) Return to the previous dose of 'maintenance therapy'.

- Amber zone: Your peak flow is less than $50 \%$ of normal or your symptom score is more than $9 .$.

(a) Start oral prednisolone immediately .... mg daily and contact GP within 24 hours.

(b) Continue on this dose until you return to your highest reading.

(c) Reduce oral prednisolone to ... mg daily for the same number of days.

(d) Stop prednisolone.

- Red zone: Your peak flow is less than $30 \%$ or your score is over $12 \ldots$
(a) Contact GP urgently, or if unavailable
(b) Go directly to hospital or if unable
(c) Call an ambulance.

The nurse observed the child's inhaler technique and corrected or revised it if necessary. Patients received a brief explanation of the mechanisms of their asthma and the functions of their medications. Each patient, and their parent, were taken through a self management plan based on the child's medications and instructed on how to use it. Patients were given a peak flow meter (fig A) and diary card (fig B) to record their symptoms, peak expiratory flow (PEF), and medications. The diary card was specifically designed to reinforce the information discussed by the nurse and to guide patients through their self management plan.

Colour coded stickers were placed on the patient's peak flow meter at levels that coincided with the self management plan (fig A). The interview usually took 45 minutes. If the nurse felt the medication needed adjusting she consulted the patient's paediatrician or a doctor on the ward.
WARD MANAGEMENT

Ward management, consisting of care by paediatric nursing staff and resident, registrar, and consultant medical staff continued as usual as did outpatient follow up appointments of 15 minutes by resident and consultant medical officers. The nurse interview was additional to these normal practices. Over the next 12 months patients were sent a letter at intervals of three months reminding them that it was time to have their asthma reviewed by their general practitioner or practice nurse. The letter suggested they should have their inhaler technique, diary card, and self management plans reviewed during their visit.

\section{CONTROL GROUP}

Patients randomised to the control group received a standardised interview. Patients completed a questionnaire, ${ }^{22}$ were given a peak flow meter and instructed how to use it and a different, black and white, diary card that simply recorded the symptoms, twice daily PEF and medication, but gave no guidance to the mechanisms of asthma or self management. The interview took approximately 15 minutes. No letters were sent suggesting general practitioner review.

All patients were reviewed at intervals of three months in their homes to collect and replace diary cards. To avoid the nurses influencing the patient's behaviour unduly while visiting the homes the patient was seen by a nurse/researcher who was not involved in the initial assessment and interview. Questionnaires were readministered at 12 months.

The nurse/researchers made no attempt to discuss, with either group, the patient's asthma, other than details relating to the collection of data for the study. Any queries regarding the patient's asthma were referred back to the patient's general practitioner or paediatrician.

\section{MEASURES}

\section{(1) Symptoms}

On each day patients rated their symptoms of night cough, night wheeze, daytime wheeze, daytime activity, and nasal symptoms from $0-3$. Morbidity was measured by calculating a symptom score for the period recorded and dividing by the number of days recorded.

\section{(2) Peak expiratory flow}

The total number of peak flow readings corresponding to the self management zones was calculated, that is, $100-70 \%, 70-50 \%$, $50-30 \%$, and less than $30 \%$ of the best PEF. This total was divided by the number of days the patient recorded. The results are expressed as the proportion of time the patient's recordings were in the respective zones.

(3) Medications, time lost from school, and visits to the general practitioner

The total number of doses/puffs of medication were recorded for each day. The total medication dosage recorded during the study was divided by the number of days recorded. Oral steroids, nebulisations, time lost from school, 
and visits to the doctor are expressed as an annual rate.

\section{(4) Patient/parent response to acute episodes}

To compare the efficiency of patient/parental response to acute episodes the number of episodes where PEF fell below $70 \%$ of best was recorded. For each episode the response by the patient/parent was coded as excellent (complete compliance with self management plan or medication regimen), appropriate (action was taken by patient or parents to increase medication or seek medical help but was at odds with their self management plans or medication regimen), or inappropriate (patient/parent ignored self management plans or medication regimens, received antibiotics as first line treatment for acute exacerbations or failed to seek medical assistance when PEF was less than $30 \%$ of personal best).

\section{(5) Questionnaires}

The morbidity questionnaire was administered after patients had completed 12 months of the study. This enabled comparison of the medical services used over the previous six month period.

\section{GENERAL PRACTITIONER INVOLVEMENT}

The support of the general practitioners in the district was essential to the success of the project. One hundred and eleven general practitioners who were in the hospital catchment area were sent a letter outlining the nature of the study. General practitioners and practice nurses were also invited to a series of meetings before the start of the study to discuss their involvement and the principles of asthma self management that would be used in the intervention group. General practitioners and practice nurses were also mailed newsletters throughout the study outlining the progress of the project.

\section{STATISTICAL ANALYSES}

Analyses were performed using the statistical packages SPSS/PC+ version 3.1. ${ }^{23}$ Differences between the nurse intervention and the control group were analysed using the Mann-Whitney $\mathrm{U}$ test. The median and interquartile ranges of each variable are presented. The confidence

Table 1 Characteristics of the children: baseline data. Values are number (\%) except where stated otherwise

\begin{tabular}{lcc}
\hline & $\begin{array}{c}\text { Control } \\
\text { group } \\
(n=43)\end{array}$ & $\begin{array}{c}\text { Nurse } \\
\text { (intervention) } \\
\text { group } \\
(\boldsymbol{n}=48)\end{array}$ \\
\hline Mean age (years) & $6 \cdot 2$ & $6 \cdot 8$ \\
M:F & $24: 19$ & $28: 20$ \\
Age of onset (years) & $1 \cdot 8$ & $2 \cdot 4$ \\
Duration of asthma (years) & $4 \cdot 3$ & $4 \cdot 3$ \\
Atopic & $22(50)$ & $30(64)$ \\
Using prophylaxis & $30(70)$ & $36(76)$ \\
Spacer used & $17(39)$ & $21(45)$ \\
Symptoms & $14(31)$ & $19(40)$ \\
Wheeze attacks (more than two per week) & $10(23)$ & $17(36)$ \\
Nocturnal attacks (more than two per week) & $21(50)$ & $28(60)$ \\
Dyspnoea walking on level & $24(65)$ & $33(83)$ \\
No of children absent from school in previous six months & $24(55)$ & $30(65)$ \\
Use of medical services & $12(27)$ & $19(41)$ \\
General practitioner home visits in previous six months & $23(53)$ & $27(57)$ \\
Casualty visits in previous six months & & \\
Hospital admission in previous six months & & \\
\hline
\end{tabular}

intervals were calculated using the microcomputer programme developed by Gardner. ${ }^{24} 25$

Within the intervention group the results were analysed separately by whether or not the patient used inhaled steroids. The inhaled steroid group were further subdivided into patients who were instructed by the paediatrician to double their inhaled steroids at the $70 \%$ level and those that were told only to increase their use of bronchodilators.

\section{Results}

The study ran for two years. Thirty seven general practitioners and 20 practice nurses representing 45 of the 57 practices in the district were involved in the initial meetings. In the first year 91 patients were enrolled, 32 outpatients and 59 inpatients. These patients were monitored for the next 12 months. Two patients declined to participate in the study, one because of the recent death of a sibling, the second because the child had diabetes and the mother felt that she could not cope with monitoring asthma as well as diabetes.

\section{CHARACTERISTICS OF THE CHILDREN}

The characteristics of the children are outlined in table 1 . In terms of age, sex, atopy, medications used, and duration and onset of asthma the two groups were well matched.

Eighty patients completed questionnaires at the beginning and the end of the study. Twelve patients $(13 \%)$, six in the nurse group and six in the control group, did not participate in the study after the initial interview. Those patients who dropped out had similar characteristics to those who completed the study.

Analysis of the questionnaires completed before entering the study (table 1) showed no significant differences between the intervention and control group for prevalence of symptoms, disability, time lost from school, or use of medical services. A high level of morbidity was evident in both groups. Between 65 and $85 \%$ of children had missed a mean of $5 \cdot 3$ to $7 \cdot 3$ days of school because of their asthma in the previous six months.

As expected there was some differences in the initial questionnaire responses between those patients who had recently been admitted and those enrolled through outpatients. Those recently admitted had significantly more casualty attendances $(p<0.05$, median difference between the groups $0.38,95 \%$ confidence interval (CI) 0.22 to 0.54 ) and hospital admissions $(p<0.05$, median difference between the groups $0.7,95 \% \mathrm{CI} 0.56$ to 0.85 ). There were no significant differences in those experiencing disability or missing time from school.

\section{DIARY CARD INFORMATION}

Information from the diary cards regarding symptoms, peak flow and medications is summarised in table 2 .

A comparison between the two groups using the Mann-Whitney $U$ test was significant $(p<0.05)$ for activity restriction (median difference between the groups $-0.17,95 \%$ CI -0.27 to -0.01 ) and time spent with lung function less than $30 \%$ of best (median 
Table 2 Morbidity measured by patient asthma diary during intervention. Values are median scores (interquartile range)

\begin{tabular}{|c|c|c|}
\hline & $\begin{array}{l}\text { Control } \\
\text { group } \\
(n=37)\end{array}$ & $\begin{array}{l}\text { Nurse } \\
\text { (intervention) } \\
\text { group } \\
(n=42)\end{array}$ \\
\hline Days recorded & $268(135-357)$ & $297(192-354)$ \\
\hline $\begin{array}{l}\text { Median daily score } \\
\text { Night wheeze } \\
\text { Day wheeze } \\
\text { Activity restriction } \\
\text { Nasal }\end{array}$ & $\begin{array}{l}0.25(0.1-0.7) \\
0.22(0.18-0.65) \\
0.13(0.04-0.4) \\
0.55(0.31-1.0)\end{array}$ & $\begin{array}{l}0.15(0.06-0.43) \\
0.26(0.85-0.47) \\
0.06(0.03-0.2)^{\star} \\
0.53(0.3-0.8)\end{array}$ \\
\hline $\begin{array}{l}\text { Daily lung function } \\
\% \text { Of time: }\end{array}$ & & \\
\hline $\begin{array}{l}\text { Above } 70 \% \text { of best PEF } \\
\text { Between } 70 \text { and } 50 \% \text { of best PEF } \\
\text { Between } 50 \text { and } 30 \% \text { best PEF } \\
\text { Less than } 30 \% \text { best PEF }\end{array}$ & $\begin{array}{l}88(70-99) \\
10(1-19) \\
1(0-7) \\
0.2(0-0.9)\end{array}$ & $\begin{array}{l}94(84-98) \\
5(1 \cdot 8-11) \\
0 \cdot 4(0-2 \cdot 7) \\
0(0-0 \cdot 1)^{\star}\end{array}$ \\
\hline $\begin{array}{l}\text { Median daily drug use } \\
\text { Puffs of bronchodilator } \\
\text { Puffs of inhaled steroid } \\
\text { Days of oral steroid used/patient/year }\end{array}$ & $\begin{array}{l}1 \cdot 7(0 \cdot 8-3 \cdot 5) \\
1 \cdot 9(0 \cdot 02-4) \\
0(0-12 \cdot 5)\end{array}$ & $\begin{array}{l}1 \cdot 9(0 \cdot 7-3 \cdot 2) \\
2 \cdot 4(1 \cdot 7-4 \cdot 3) \\
2 \cdot 0(0-8 \cdot 1)\end{array}$ \\
\hline $\begin{array}{l}\text { School absenteeism and general practitioner visiting } \\
\text { Days lost from school/patient/year } \\
\text { Consultations with general practitioner/patient/year }\end{array}$ & $\begin{array}{l}4 \cdot 7(0-10) \\
2(0 \cdot 5-5 \cdot 3)\end{array}$ & $\begin{array}{l}2 \cdot 1(0-6 \cdot 9) \\
2 \cdot 3(0-4 \cdot 9)\end{array}$ \\
\hline $\begin{array}{l}\text { Patient/parent response to acute attack } \\
\% \text { Of attacks with: } \\
\text { Excellent response } \\
\text { Appropriate response } \\
\text { Inappropriate response }\end{array}$ & $\begin{array}{l}45 \cdot 5(11 \cdot 1-83) \\
25(0-43 \cdot 8) \\
9(0-50)\end{array}$ & $\begin{array}{l}78(57-100)^{\star \star} \\
12 \cdot 5(0-25) \\
0(0-11 \cdot 1)^{\star}\end{array}$ \\
\hline
\end{tabular}

${ }^{\star} \mathrm{p}<0.05 ;{ }^{\star \star} \mathrm{p}<0.005$.
USE OF MEDICAL SERVICES

Information from the questionnaire administered at the end of the study was used to determine the use of medical services over the previous six months. In the control and intervention groups home visits by the general practitioner were required by 31 and $23 \%$ of patients respectively. Interestingly a higher proportion of patients in the intervention group required hospital admission (12\%) compared with the control group (3\%). Once again, however, these differences did not reach statistical significance.

\section{Discussion}

The participation of patients and staff in the project and the interest of health care groups in the community suggests the nurse run asthma clinic using a colour coded self management plan was an acceptable addition to the district's services.

The intervention and control groups were well matched not only for age and sex but for asthma severity, medications used, atopy, and duration of asthma. We were only able to demonstrate statistically significant results in two of the morbidity variables examined. The other parameters showed a tendency towards improvement. While this represents only limited gains, the study has highlighted a number of aspects which might further improve the outcome.

Other studies principally from America have achieved similar results but with a far greater expenditure in time and resources. ${ }^{12} 2627$ The University of Alabama, Birmingham, programme described by Bailey et al involved six hours of patient education and several group sessions. ${ }^{27}$ Our results were achieved with one 45 minute consultation at the time of admission or during routine outpatient appointments, and a structured review by the general practitioner. This did not involve any additional general practitioner time as evident by the similarity in general practitioner surgery visiting between the two groups. Several studies have demonstrated success when patients are allocated to an asthma specialist and have the intervention sustained. ${ }^{28} 29$ Our programme may well have benefited from more intensive follow up by an asthma nurse.

Had our patients been instructed to increase their treatment at $80 \%$ of best PEF rather than $70 \%$ and had all patients been placed on self management plans that doubled inhaled steroids as a first step then a greater difference may have been evident between the two

Table 3 Comparison of self management groups. Values are median scores (interquartile range)

\begin{tabular}{|c|c|c|c|c|}
\hline & \multirow[b]{2}{*}{$\begin{array}{l}\text { Control group } \\
(n=37)\end{array}$} & \multicolumn{3}{|c|}{ Nurse (intervention) subgroups } \\
\hline & & $\begin{array}{l}\text { Inhaled steroid: } \\
\text { increase steroid } \\
(n=17)\end{array}$ & $\begin{array}{l}\text { Inhaled steroid: } \\
\text { increase bronchodilator } \\
(n=16)\end{array}$ & $\begin{array}{l}\text { Non-steroid } \\
(n=7)\end{array}$ \\
\hline \multirow{2}{*}{$\begin{array}{l}\text { Night wheeze } \\
\text { Day wheeze } \\
\text { Days of oral steroid used/patient/year } \\
\text { Days lost from school/patient/year } \\
\text { Consultations with general practitioner/ } \\
\text { patient/year }\end{array}$} & $\begin{array}{l}0.25(0.1-0 \cdot 7) \\
0 \cdot 26(0 \cdot 09-0 \cdot 47) \\
0(0-12 \cdot 5) \\
4 \cdot 7(0-10)\end{array}$ & $\begin{array}{l}0.11(0.05-0.6) \\
0.15(0.09-0.72) \\
0(0-7.3) \\
1.5(0-4 \cdot 1)\end{array}$ & $\begin{array}{l}0.16(0.05-0.5) \\
0.3(0.05-0.5) \\
3(0-12 \cdot 8) \\
4.5(0.5-12)\end{array}$ & $\begin{array}{l}0.12(0.07-0.3) \\
0.36(0.13-0.45) \\
4.1(0-23 \cdot 2) \\
3.6(1.4-8.0)\end{array}$ \\
\hline & $2(0 \cdot 5-5 \cdot 3)$ & $1(0-3 \cdot 8)$ & $2 \cdot 8(0 \cdot 5-5 \cdot 6)$ & $4 \cdot 6(3 \cdot 4-13 \cdot 5)$ \\
\hline
\end{tabular}


groups. Research by Beasley et al has demonstrated the benefit of twice daily inhaled steroids that are doubled if the asthma deteriorates. ${ }^{18}$ Studies by our group have confirmed these findings ${ }^{19}$ but also concluded that changing treatment at $\mathbf{8 0} \%$ is more appropriate and may further improve morbidity. Such an adjustment to the management plan would see the patient intervening earlier in an asthma attack. Woolcock et al demonstrated considerable short and medium term benefits by maintaining a patient's peak flow as close to maximum as possible. ${ }^{30}$ Such an objective may also have long term advantages in minimising the risk of irreversible lung disease. ${ }^{31}$

Of particular interest was the reduction in home visits by the general practitioner and time lost from school as these have obvious resource implications for the district. Our study did not demonstrate a reduction in readmissions. The rise in readmissions may reflect patients with severe asthma now seeking hospitalisation where as before our programme such patients may have ignored their condition and remained in the community at greater risk of death. ${ }^{32}$

Even though the nurse intervention may have had some impact on modifying patient morbidity it is clear that many patients were experiencing severe persistent symptoms and that the admission represented only the 'tip of the iceberg'. Before the admission 55\% reported dyspnoea walking on the level and $25 \%$ had more than two nocturnal attacks per week. Despite our intervention and the tendency for the asthma to improve with time, many of the patients continued to have limitation of activity and disturbed sleep.

The majority of patients required a single admission, only $7 \%$ being readmitted. These admissions were relatively short, averaging only two days. ${ }^{33}$ In fact most patients would arrive in the late afternoon and then be discharged the next morning. This very short period in hospital normally provides little time for any education or understanding of why the patient's asthma had deteriorated. The normal routine surrounding an admission is inadequate for effective communication especially when the accompanying parent is tired, anxious, and keen to return home to the rest of the family. We feel that the specially trained nurse with specific tasks was able to overcome some of these obstacles and provide the necessary time to listen and explain the management goals to the patient.

The newsletter to general practitioners, evening meetings for the general practitioner team, and the diary card aimed to improve communication between primary and secondary care. Letters sent to patients reminding them to attend their general practitioners helped raise patients' expectations about what they should receive from general practitioners in a follow up and similarly helped general practitioners understand their role in the care of the patient. These measures were generally well received. A number of parents commented that since having the diary card they were now able to speak to their general practitioners and were surprised to find their general practitioners actually did care about their child's asthma!

Overall the project appealed to the patients with only two declining to participate and $13 \%$ withdrawing after the initial visit. The median number of days recorded was 283 from a possible 365. Patients in the nurse intervention group were more likely to implement their treatment according to their self management plans and less likely to make inappropriate responses to acute attacks.

This study was unusual in that techniques developed in general practice were adopted in a hospital setting. The project purposefully avoided trying to extend the hospital activity into the community and enlisted the help of the general practitioner community from the outset. This was an inreach rather than an outreach programme. The project attempted to improve the way primary and secondary care interacted and communicated. Much has been written about the problems resulting from poor communication between primary and secondary care. ${ }^{34} 35$ We felt it essential that these problems be addressed to enable the clinic to function properly.

Future research may wish to explore the interaction of primary and secondary care where the patient acts as mediator. It was hoped that the diary card and reminder letters facilitated the transfer of information between the hospital, the patient, and the primary health care team. It would be interesting to explore whether the diary card influenced the general practitioner's own management policies in relation to other patients within their practice.

\section{CONCLUSION}

The asthma clinic run by a nurse showed a tendency to modify symptoms and peak flow as compared with the control group. Although only two variables were significantly different, the other variables confirmed this trend. The greatest benefit of the intervention seems to have been derived by the 17 patients who doubled their inhaled steroids as their peak flow and symptoms deteriorated. Patients who attended the nurse were more likely to make the correct response to an acute exacerbation.

By raising the level at which patients increase their inhaled steroids to $80 \%$ of their best PEF and increasing the intensity of follow up further improvements in outcome might be achieved. Although the intervention did not reduce hospital admissions the decrease in school absenteeism may be justification for such a project.

The project highlighted the importance of coordinating care between the hospital, the patient, and the primary health care team.

The authors would like to thank $3 \mathrm{M}$ Healthcare, the Wessex Regional Health Authority, and the Wessex Medical Schoo Trust for funding the study. We are also indebted to Astra Pharmaceuticals, Boehringer Ingleheim, Allen and Hanburys, and Fison's Pharmaceuticals for their support throughout the project. Professor Roger Jones's expert supervision was gratefully appreciated.

The diary cards are available in the UK from the Marketing Department, 3M Health Care (UK), Loughborough, Leicestershire LE11 1EP (telephone 0509611611 ) and from Dr Ian Charlton, 7 Tilba Street, Kincumber, 2251, NSW, Australia (fax (010) 61-43-631664). 
1 Burney PGJ. Asthma mortality in England and Wales: evidence for a further increase. Lancet 1986; ii: $323-6$.

2 Fleming DM, Crombie DL. Prevalence of asthma and hay fever in England and Wales. BMF 1987; 294: 279-83.

3 Hill RA, Standen PJ, Tattersfield AE. Asthma, wheezing and school absence

1989; 64: 246-51.

Keating G, Mitchell EA, Jackson R, et al. Trends in sales of drugs for asthma in New Zealand, Australia and the United Kingdom. BMF 1984; 289: 348-51.

5 Anderson HR. Is the prevalence of asthma changing? Arch Dis Child 1989; 64: 172-5.

6 Storr J, Barrell E, Lenney W. Rising asthma admissions and self referral. Arch Dis Child 1988; 63: 774-9.

7 Sibbald B. Patient self care in acute asthma. Thorax 1989 44: 97-101.

8 Anderson HR, Freeling P, Patel SP. Decision-making in acute asthma. f $R$ Coll Gen Pract 1983; 33: 105-8.

9 Bucknall CE, Robertson C, Moran F, Stevenson RD. Management of asthma in hospital: a prospective audit. Management of asthma

10 Anderson HR, Bailey P, West S. Trends in the hospital care of acute childhood asthma 1970-8: a regional study. $B M \mathcal{F}$ 1980; 281: 1191-4.

11 Anderson HR, Bailey PA, Cooper JS, Palmer JC. Influence of morbidity, illness label and social, family, and health service factors on drug treatment of childhood asthma. Lancet 1981; ii: 1030-2.

12 Clark NM, Feldman CH, Evans D, et al. Managing better: children, parents and asthma. Patient Education and Counselling 1986; 8: 27-37.

13 Rakos RF, Grodek MV, Mack KK. The impact of a self administered behavioral intervention program on administered behavioral intervention program

14 Fireman P, Friday GA, Gira C, Vierthaler WA, Michaels L. Teaching self-management skills to asthmatic children and their parents in an ambulatory care setting. Pediatrics 1981; 68: 341-7.

15 Hilton S, Sibbald B, Anderson HR, Freeling P. Controlled evaluation of the effects of patient education on asthma morbidity in general practice. Lancet 1986; i: 26-9.

16 Mitchell EA, Ferguson V, Norwood M. Asthma education by community child health nurses. Arch Dis Child 1986; 61: 1184-9.

17 Carswell F, Robinson EJ, Hek G, Shenton T. A Bristol experience: benefits and cost of an 'asthma nurse' visiting the homes of asthmatic children. Bristol Medico Chirurgical fournal 1989; 104: 11-2.

18 Beasley $R$, Cushley $M$, Holgate ST. A self management plan in the treatment of adult asthma. Thorax 1989; 44: $200-4$
19 Charlton I, Charlton G, Broomfield J, Mullee M Evaluation of peak flow and symptoms only self-manage ment plans for control of asthma in general practice. $B M$ 1990; 301: 1355-9.

20 Charlton I, Chariton G, Broomfield J, Mullee MA. Audit of the effect of a nurse run asthma clinic on workload and asthel clinice $\mathrm{Br} \mathscr{\jmath}$ Gen Pract 1991; 41: 227-31.

21 Charlton I, Charlton G. New perspectives in asthma care. Practitioner 1990; 234: 30-2

22 Hilton S, Sibbald B, Anderson HR, Freeling P. Evaluating health education in asthma - developing the methodology: preliminary communication. $\mathcal{F} R$ Soc Med 1982; 75: 625-30.

23 Norusis MJ. The SPSS guide to data analysis for SPSS/PC+ Chicago: Statistical Package for the Social Sciences, 1989.

24 Gardner MJ, Gardner SB, Winter PD. Confidence interval analysis (CLA) microcomputer program manual. Version 1.0 . London: British Medical Journal, 1989: 1-77.

25 Gardner MJ, Campbell M. Statistics with confidence. BMF 1988; 224: 1454-6.

26 Avery $\mathrm{CH}$, March J, Brook RH. An assessment of the adequacy of self care by adult asthmatics. $\mathcal{f}$ Community Health 1980; 5: 167-80.

27 Bailey WC, Richards JM, Brooks CM. A randomized trial to improve self-management practices of adults with asthma. Arch Intern Med 1990; 150: 1664-8.

28 Hughes DM, McLeod M, Garner B, Goldbloom RB. Controlled trial of a home and ambulatory program for asthmatic children. Pediatrics 1991; 87: 54-61.

29 Zeiger RS, Heller S, Mellon MH, Wald J, Falkoff R, Schatz M. Facilitated referral to asthma specialist reduces relapses in asthma emergency room visits. $f$ Allergy Clin relapses in asthma emergen

30 Woolcock AJ, Yan K, Salome CM. Effect of therapy on bronchial hyperresponsiveness in the long-term management of asthma. Clin Allergy 1988; 18: 165-76.

31 Holgate ST, Finnerty JP. Recent advances in understanding the pathogenesis of asthma and its clinical implications. $Q$ f Med 1988; 66 (249): 5-19.

32 Carswell F. Thirty deaths from asthma. Arch Dis Child 1985; 60: $25-8$.

33 Charlton I. Acute admissions: how do doctors react to an emergency? Refer 1989; 1 (11): 12-3.

34 Essex B, Doig R, Renshaw J. Pilot study of records of shared care for people with mental illnesses. BMF 1990; 300: $1442-6$.

35 Leys P, Whitworth MA, Skilbeck CE. Improving doctor patient communication in general practice. $\mathcal{F} R$ Coll Gen Pract 1976; 26: 720-4. 